\title{
ON FLANDERS' HYPOTHESIS OF CASTE DETERMINATION IN ANTS*
}

\author{
BY EDWARD O. WILSON
}

Biological Laboratories, Harvard University

S. E. Flanders $(1945,1952)$ has recently advanced a hypothesis concerning caste determination in ants which has gained wide recognition. According to Flanders, the nutritive material available to the female embryo in the egg determines the developmental path it will follow as a larva, producing finally a queen or one of the worker subcastes. The available nutritive material is assumed to be a function of the degree of ovisorption, since this has been shown to be the basis of discontinuous variation in several terebrant Hymenoptera. The degree of ovisorption in turn is assumed to be a function of one or more environmental influences affecting the queen. One of the ways the environment can act is through its effect on the rate of oviposition, which is probably inversely related to the degree of ovisorption.

What appears to be the crux of Flanders' hypothesis is stated as follows in his 1952 paper: "Since the worker caste is characteristic of all non-parasitic ants, irrespective of the wide variation in the larval nutrition of the various species, it is evident that any trophic influence on caste formation must be made effective through an agency common to all ant colonies. Such an agency is most likely to consist of a set of conditions resident in the queen. Morphological differentiation would be initiated therefore prior to egg deposition."

* Dr. Flanders has recently published the paper read at the December 1952 meeting of the American Section of the International Union for the Study of Social Insects (Scientific Monthly, 76: 142-148, 1953). This contains an extensive elaboration of his hypothesis, with heavy emphasis on examples drawn from the terebrant Hymenoptera, but presents no new experimental evidence bearing on ants and does not take into account the objections raised by myself at the original reading and presented once again in the following paper. 
From the onset this line of reasoning appears weak, since it is obvious that the environment of the ovary is by no means the only condition affecting individual development which is common to all ant colonies. Colonial organization and the details of individual postembryonic development are fundamentally the same for all ants and are amenable to the establishment of any number of physiological mechanisms controlling caste differentiation. To settle on one specific mechanism without supporting evidence is to engage in almost pure speculation. Since a great deal of new information bearing on this subject has been brought to light in the past decade, a reevaluation of Flanders' suggestions and of the literature pertinent to them is warranted at the present time.

One does not need to look far to find that Flanders' hypothesis is contravened by a considerable body of evidence, much of it resting in the literature. While it is possible that the differences in yolk content which are presumed to underlie caste differentiation may be so subtle as to escape the eye of the casual myrmecological observer, it still should be taken as significant that variation in egg size and content have rarely been recorded in the literature and then have been shown definitely not to correlate with caste differentiation (Eidmann 1931, Ledoux 1950). Some effort has actually been made to demonstrate caste differences at the level of the egg, as in the work of Bhattacharya (1943) on Oecophylla smaragdina (Fabricius), but with negative results. Direct evidence against the hypothesis may be supplied by the work of Ledoux (1949, 1950) on Oecophylla longinoda (Latreille). In this species the workers act as supplementary reproductives and can produce males, queens, and major and minor workers with equal facility. Two sizes of eggs are laid, averaging in length $0.6 \mathrm{~mm}$ and $1.1 \mathrm{~mm}$ respectively. The larger size yields males, the smaller, any of the three female castes. The fecundated female, on the other hand, lays eggs all of the same size, averaging $1.2 \mathrm{~mm}$ in length, from which proceed either workers (at least) or males. Ledoux has offered the logical explanation that the smaller worker eggs produce females and not males, as would be expected 
from unfertilized eggs, because they are laid prematurely and at least some time before the first meiotic division. But whatever the explanation, the important point considered here is that workers can develop from eggs of either of the two different sizes, whereas queens develop from at least the smaller of the two sizes. While it is true that the size of the Oecophylla egg may not absolutely determine yolk content, yet it seems very probable that the differences in yolk content between two such markedly distinct egg sizes would greatly outweigh the very slight differences that must be assumed to determine caste in the workerlaid egg if Flanders' hypothesis is correct.

The preponderance of available evidence seems to indicate that the caste of female individuals is determined in the larval period, without regard to the original condition of the egg. The work of Wesson (1940), Goetsch (1937), and many others in the past half century has shown that larval feeding plays a major role; an excellent review of this work is presented by Light (1942-43). Gregg (1942) has shown that the major-minor ratio in colonies of Pheidole morrisi Forel affects significantly the ratio of these castes appearing in the brood, and he has offered as the simplest explanation that this condition originates through trophic influences, possibly ectohormonal, on the developing larvae. Recently, Brian (1951) has outlined his preliminary results from current work on caste determination in Myrmica rubra L. The threshold for queen-worker divergence is reported to be in the larval period; in order to attain queenness an overwintering larva must reach by a certain time a weight of about 6.5 milligrams. It must then race to reach another threshold in order to become a fully developed queen; if it fails, it ends its development abnormally small or as an intercaste. Ledoux (op. cit.) presents convincing evidence that in Oecophylla longinoda the threshold for queen-worker divergence is in very early larval life, while the threshold for major-minor divergence is at some time in the second larval stadium. In the work of both Brian and Ledoux it is especially noteworthy that larval nutrition and larval size are apparently the major factors involved. 
The present writer (Wilson 1953) has shown that all stages of polymorphism in ants can be explained on the basis of simple or modified adult allometry and correlated changes in the frequency distribution of size. The greater part of the differential growth underlying this allometry must occur no sooner than the prepupal stage, when the gross adult form is laid down by the proliferation and deployment of the pupal hypodermis. Certain finer details of allometry may not become apparent until later at the onset of adult development. The allometric character of the castes is obscured in the case of complete dimorphism, or queen-worker and major-minor segregation, in which the intermediates drop out and the log-log allometric regression curves of the two castes become disaligned. Dimorphism can be explained simply on the basis of abrupt changes in the specific growth rates of the imaginal discs of various organs at critical sizes or under certain physiological influences, a phenomenon which has been demonstrated to be fundamental in the ontogenetic growth of many other groups of animals (Teissier 1934, Yasumatsu 1946). Queen-worker divergence, preceding in ontogeny the allometric differentiation of the worker subcastes, probably is initiated at a critical time by the fixing in the imaginal dises of one of two alternative specific-growth-rate potentials ; this is attended by an approximate regulation of the course of larval development. A second threshold of this type may be introduced at a later stage of larval development in the case of major-minor dimorphism. As stated previously, the important specific-growth-rate potentials are completely expressed only at or after the onset of pupal development prior to the last larval ecdysis. This means that differentiation of female castes at all levels is probably a function of size, whether in the attainment of a threshold size in larval development, in the case of dimorphism, or in the relation of gradient allometric growth to the total size reached at the termination of larval development, in the case of the more elementary stages of polymorphism.

If an attempt is made to fit Flander's hypothesis to this concept, it seems to force the proposition that the nutritive 
material in the egg determines caste by predetermining exactly the size reached by a larva at various stages of its development. Such a proposition would be wrong, of course, since it is a commonly observed fact that the growth of larvae can be changed greatly by simply varying the amount and kind of food supplied the colony. It appears to the present writer that Flanders' explanation has a good chance of holding only under certain conditions of complete dimorphism. It is not impossible that in extreme cases the critical developmental time mentioned above can be pushed back in ontogeny all the way through the larval period and to the embryonic period within the egg, so that the imaginal disc potentials are already fixed at the time of eclosion from the egg. On the other hand, ovisorption might exercise a subsidiary influence in caste determination by statistically affecting the chances of a larva attaining the important size levels during its growth; existing data on larval development are not complete enough to evaluate this particular aspect. Whether ovisorption ever actually plays these two roles remains to be seen, but at the present time this outstanding fact must be accepted: there is no direct evidence upon which to base such an assumption.

Bhattacharya, G. C.

\section{Literature Cited}

1943. Reproduction and caste determination in aggressive red-ants Oecophylla smaragdina Fab. Bose-Research Institute, Calcutta.

BRIAN, M. V.

1951. Caste determination in a myrmicine ant. Experientia, 7: 1-4.

EIDManN, H.

1931. Die Koloniegründung von Lasius flavus F. nebst weiteren Untersuchungen über die Koloniegründung der Ameisen. Biol. Zentralbl., 51: 657-677.

Flanders, S. E.

1945. Is caste determination in ants a function of the rate of egg deposition? Science, 101: 245-246.

1952. Ovisorption as the mechanism causing worker development in ants. Jour. Econ. Ent., 45: 37-39.

Goetsch, W.

1937. Die Entstehung der "Soldaten" im Ameisenstaat. Naturwissensch., hrsg. A. Berliner, 25: 803-808. 
GREGG, R. E.

1942. The origin of castes in ants with special reference to Pheidole morrisi Forel. Ecology, 23: 295-308.

LEDOUX, A.

1949. La ponte des ouvrières de la fourmi fileuse Oecophylla longinoda (Latr.). C. R. Acad. Sci., Paris, 228: 1154-1155.

1950. Recherche sur la biologie de la fourmi fileuse (Oecophylla longinoda Latr.). Ann. Sci. Nat., Zool., 12: 312-461.

LIGHT, S. F.

1942-1943. The determination of the castes of social insects. Quart. Rev. Biol., 17: 312-326; 18: 46-63.

TeIssIer, G.

1934. Dysharmonies et discontinuities dans la croissance. Herman and Co., Paris. 39 pp.

WILSON, E. O.

1953. The origin and evolution of polymorphism in ants. Quart. Rev. Biol., in press.

YaSUMATSU, $\mathrm{K}$.

1946. Some analyses on the growth of insects with special reference to a phasmid, Phraortes kumamotoensis Shiraki (Orthoptera). Jour. Dept. Agric. Kyushu Imp. Univ., 8: 1-579. 

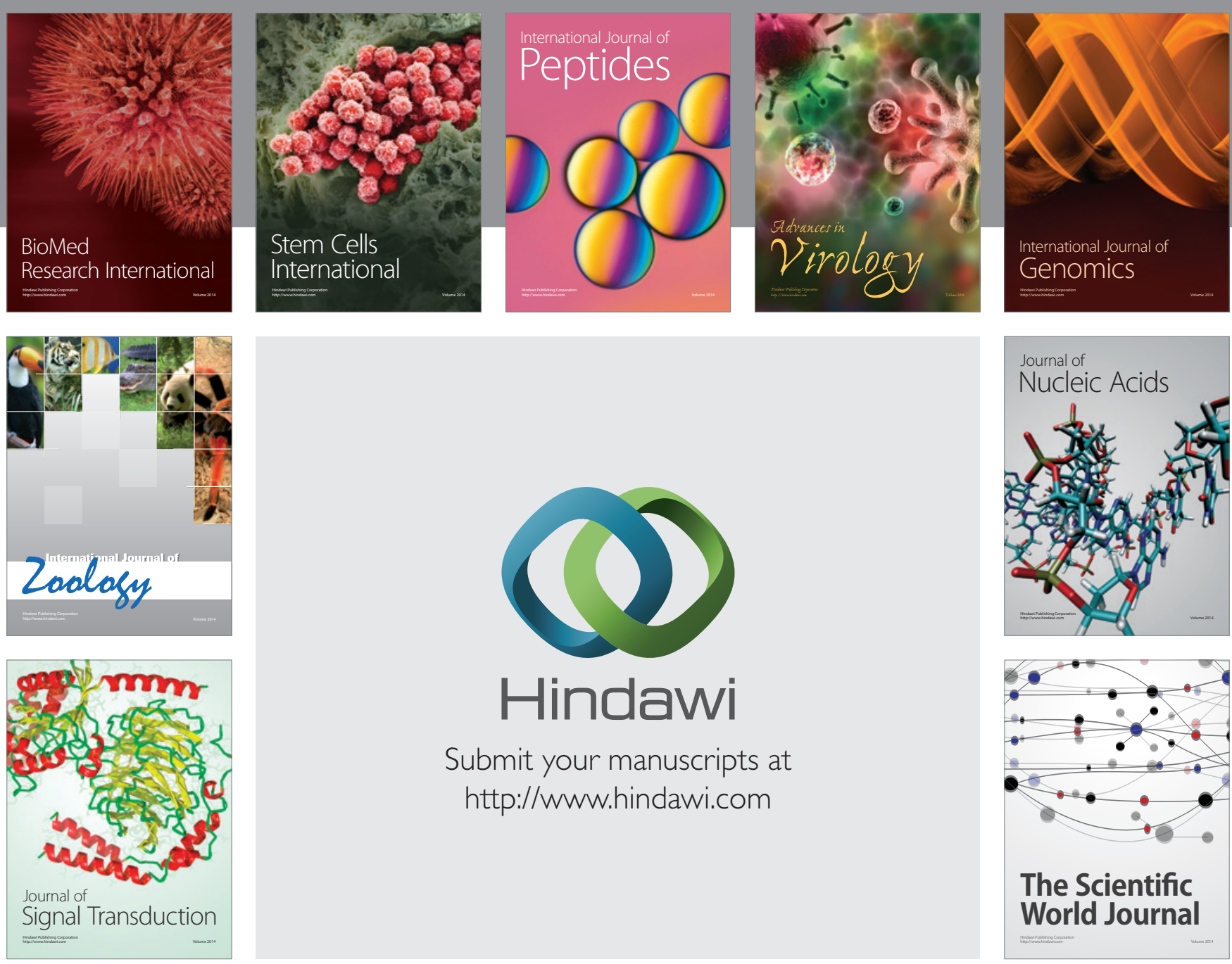

Submit your manuscripts at

http://www.hindawi.com
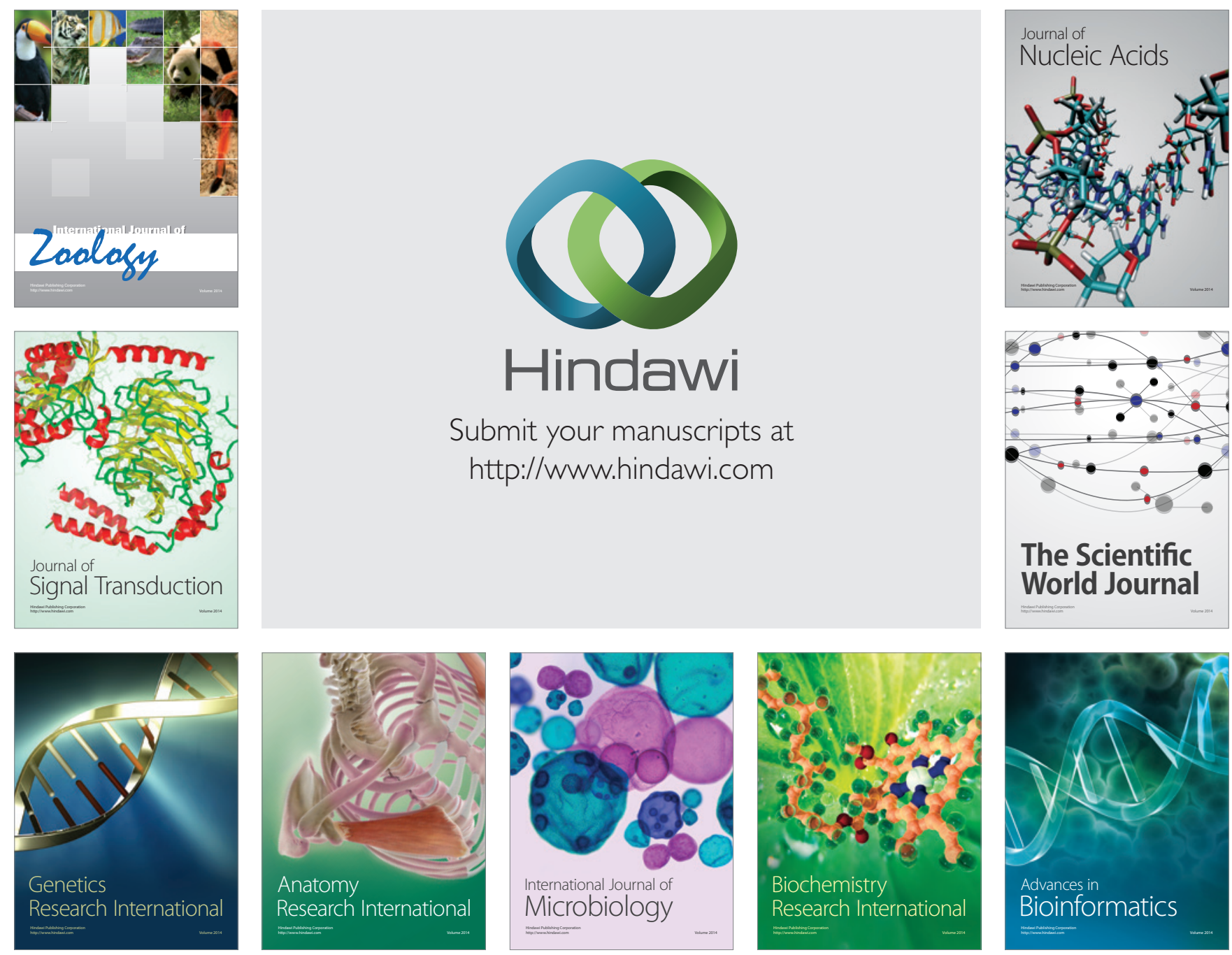

The Scientific World Journal
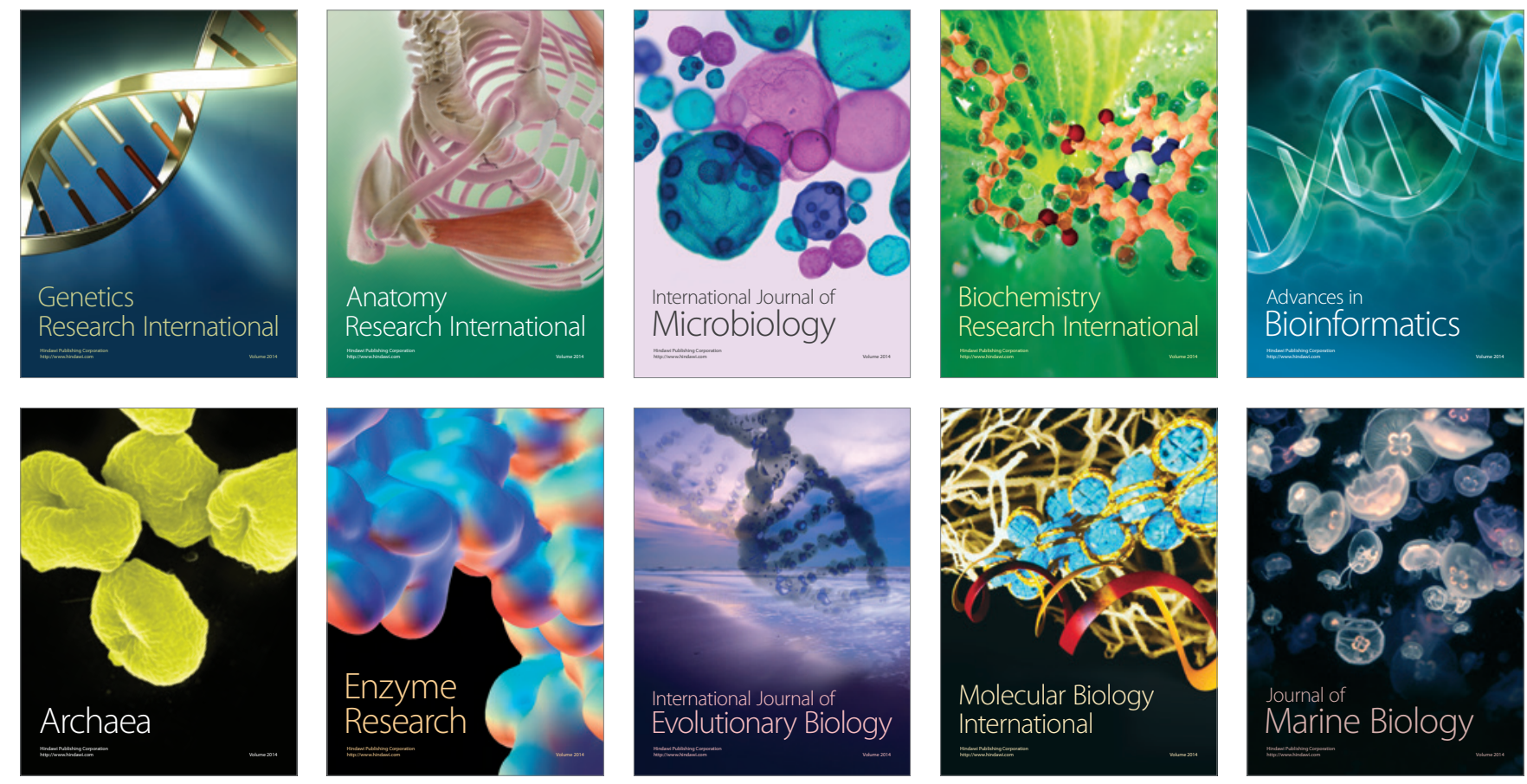